\title{
Oral and pharyngeal bolus transit in patients with chronic obstructive pulmonary disease
}

\author{
This article was published in the following Dove Press journal: \\ International Journal of COPD \\ 5 March 2015 \\ Number of times this article has been viewed
}

\author{
Rachel Aguiar Cassiani \\ Carla Manfredi Santos \\ José Baddini-Martinez \\ Roberto Oliveira Dantas \\ Department of Medicine, Medical \\ School of Ribeirão Preto, University \\ of São Paulo, Ribeirão Preto, São \\ Paulo, Brazil
}

Background: Patients with respiratory diseases, such as chronic obstructive pulmonary disease (COPD), may have swallowing dysfunction.

Objective: The aim of this investigation was to evaluate the oral and pharyngeal phases of swallowing in patients with COPD.

Methods: We studied 16 patients with clinical manifestations and pulmonary function tests diagnosis of COPD (mean age: 68 years) and 15 nonsmoking healthy volunteers (mean age: 65 years) with normal pulmonary function tests. All subjects were submitted to clinical and videofluoroscopic evaluation of swallowing. Each subject performed in duplicate swallows of $5 \mathrm{~mL}$ and $10 \mathrm{~mL}$ of liquid bolus, paste bolus, and a solid bolus.

Results: In general, the duration of the events of the pharyngeal phase of swallowing was longer in COPD patients than controls. The difference was significant in the laryngeal vestibular closure, hyoid movement, and pharyngeal transit with swallows of both volumes of liquid bolus; in oral-pharyngeal transit with $5 \mathrm{~mL}$ paste bolus; and in pharyngeal and oralpharyngeal transit with solid bolus. The difference between the duration of maximal laryngeal elevation and the duration of pharyngeal transit was higher in control subjects than in patients with COPD.

Conclusion: The results suggested that patients with COPD have a longer pharyngeal swallowing phase than normal subjects, which is associated with a decrease in the difference between the duration of maximal laryngeal elevation and the duration of pharyngeal transit.

Keywords: COPD, videofluoroscopy, oral-pharyngeal transit, swallowing, deglutition

\section{Introduction}

Chronic obstructive pulmonary disease (COPD) is a disorder characterized by chronic obstruction of the pulmonary airflow, with little variation in time and slow progression, associated with an inflammatory response to environmental particles or gases, in particular to cigarette smoke. ${ }^{1}$ The limitation of the expiratory flow is compensated greatly by an increase in the work of respiratory muscles, particularly those activated during inspiration. ${ }^{2}$ The patients have a limited ventilatory capacity with increased respiratory frequency during rest and poor exercise tolerance mainly due to dyspnea. ${ }^{1}$

Respiration and swallowing are related and coordinated to reach a safe transit of food through the pharynx. ${ }^{3}$ The loss of respiration-swallowing coordination may cause dysphagia, aspiration, pneumonia, malnutrition, dehydration, decrease in quality of life, and death. ${ }^{4}$

Some studies have shown that patients with COPD may have swallowing dysfunction, with the possibility of airway penetration and aspiration. ${ }^{5-7}$ Abnormal swallowing reflex frequently occurs and predisposes patients to disease exacerbations. ${ }^{8}$ Patients with COPD have a longer than expected apnea during the oral-pharyngeal 
transit, which may cause problems in respiration during meals. ${ }^{9}$ These patients swallow at points during the respiratory cycle that can promote aspiration, ${ }^{10}$ as the occurrence of inspiration before swallowing, followed by inspiration after swallowing, increases the risk for laryngotracheal aspiration. $^{11}$

Dysphagia is a complaint in $17 \%$ of COPD patients, with an increased possibility of pharyngeal residues and aspiration after swallowing. ${ }^{6}$ Limited laryngeal elevation, a decrease in tongue force and tongue movement, and a delay in swallowing reflex are the most frequent alterations of swallowing in these patients. ${ }^{5}$

The objective of this study was to evaluate the oral and pharyngeal phases of swallowing in patients with COPD, with the hypothesis that patients with COPD have an alteration of oral and pharyngeal bolus transit, which may contribute to weight loss.

\section{Material and methods}

We studied 16 patients with COPD, aged 56-77 years (mean 68 years), one women (6\%) and 15 men (94\%), weight 71.4 (standard deviation [SD] 11.3) kg, and body mass index 26.8 $(\mathrm{SD} 5.0) \mathrm{kg} / \mathrm{m}^{2}$. They had moderate $(\mathrm{n}=2)$ or severe $(\mathrm{n}=14)$ disease, were in a stable phase of the disease, reported a smoking habit in the past, but had quit the habit at least 6 months before the investigation. Spirometry and arterial blood gases in room air were performed within 3 months before the date of assessment of swallowing. All tests were compatible with a diagnosis of COPD (Table 1). The patients were recruited from an ambulatory respiratory clinic of a tertiary care center in Ribeirão Preto (São Paulo, Brazil) during a 1-year period.

The control group was composed of 15 normal volunteers, aged $57-73$ years (mean 65 years), three women $(20 \%)$ and 12 men (80\%) who did not smoke in the past 10 years, weight 76.2 (SD 8.2) kg, and body mass index 27.7 (SD 3.0) kg/m². They were recruited from the community and submitted

Table I Pulmonary function parameters of the subjects enrolled in the study

\begin{tabular}{|c|c|c|c|c|}
\hline & \multicolumn{2}{|l|}{ COPD } & \multicolumn{2}{|l|}{ Controls } \\
\hline & Range & Mean (SD) & Range & Mean (SD) \\
\hline $\mathrm{FEV}_{1}(\%)$ & $24.6-55.2$ & $40.2(8.1)$ & $77.9-126.9$ & $98.5(12.7)$ \\
\hline FVC (\%) & $21.6-101.2$ & 69.5 (19.5) & $74.9-129.0$ & $98.7(12.4)$ \\
\hline $\mathrm{FEV}_{1} / \mathrm{FVC}$ & $29.3-62.8$ & $43.1(10.1)$ & $70.0-90.5$ & $76.9(5.8)$ \\
\hline Arterial $\mathrm{pH}$ & $7.39-7.50$ & $7.43(0.03)$ & - & - \\
\hline $\mathrm{PaO}_{2}(\mathrm{mmHg})$ & $64.0-84.7$ & 71.1 (7.8) & - & - \\
\hline $\mathrm{PaCO}_{2}(\mathrm{mmHg})$ & $33.8-45.1$ & 38.1 (2.9) & - & - \\
\hline
\end{tabular}

Abbreviations: COPD, chronic obstructive pulmonary disease; FEV , forced expiratory volume in I second; FVC, forced vital capacity; SD, standard deviation. to spirometry, the results of which were always within the normal ranges (Table 1). The study was approved by the Ethics Committee of the Medical School of Ribeirão Preto, University of São Paulo, and written informed consent was obtained from all subjects.

For both groups, individuals with evidence of other pulmonary diseases such as asthma and tuberculosis sequelae were excluded, as well as those with other significant diseases such as severe heart disease, cancer, diabetes, hypertension, severe arterial disease, stroke, or other neurologic conditions. None of the patients or the volunteers had symptoms of gastroesophageal reflux disease, dysphagia, or oral-pharyngeal dysfunction. The volunteers of the control group did not have dyspnea or cough.

\section{Pulmonary function tests}

Both the COPD and control group were submitted to spirometry (Table 1) for the diagnosis of COPD and the classification of severity. The test was performed on a Pulmonet III spirometer (Sensormedics, Anaheim, CA, USA), according to the recommendations of the American Thoracic Society. The parameters analyzed were forced vital capacity (FVC), forced expiratory volume in 1 second $\left(\mathrm{FEV}_{1}\right)$, and Tiffeneau index $\left(\mathrm{FEV}_{1} / \mathrm{FVC}\right)$.

The results of the spirometric parameters were expressed according to the percentage predicted for age, height, and sex based on the equations of Crapo et al. ${ }^{12,13}$ The diagnosis of COPD was established when the Tiffeneau index was less than $70 \%$, even after bronchodilator use, according to GOLD criteria. ${ }^{1}$ The disease was classified as moderate when $\mathrm{FEV}_{1}$ was between $50 \%$ and $80 \%$ of the predicted value and considered severe when it was between $30 \%$ and $50 \%$ of the predicted value.

\section{Arterial blood gases analysis}

Arterial blood gas analysis was done in the group of patients with COPD. Blood samples to measure arterial blood gases were obtained in ambient air from a radial artery puncture of an upper limb. The heparinized blood samples were promptly analyzed in a Corning 178 gas analysis apparatus.

\section{Videofluoroscopy evaluation}

The equipment used to perform videofluoroscopy was an Arcomax angiograph unit (model BV 300; Phillips, Veenpluis, the Netherlands). The images were recorded in digital form on the unit EDSR 100, v.1.2 Everfocus ${ }^{\circledR}$ (Taipei, Taiwan) and analyzed on a monitor of the same manufacturer. The 
apparatus recorded 60 frames/second. The maximum radiation exposure duration during videofluoroscopy was 120 seconds. The digital clock of the apparatus indicates time in minutes, seconds, and the number of frames on each video frame.

The examination was performed with the subjects in the sitting position, with the feet flat on the floor and the trunk straight (angle near $90^{\circ}$ ) and inline with the legs, and image capture of the mouth, pharynx, and proximal esophagus in lateral-right position. Volunteers and patients swallowed in duplicate $5 \mathrm{~mL}$ and $10 \mathrm{~mL}$ each of liquid and paste boluses, as well as a solid bolus. For liquid bolus, we used the liquid barium sulfate (Bariogel ${ }^{\circledR} 100 \%$; Laboratory Cristália, Itapira, São Paulo, Brazil) which was presented to the individual in a graduated syringe. It had the consistency of thick liquid. For the preparation of the paste consistency, $30 \mathrm{~mL}$ of liquid barium sulfate was mixed with $3 \mathrm{~g}$ of Nutilis food thickener (Cuyk Nutricia BV, Cuyk, the Netherlands) in a pudding consistency, which was presented to the patient by spoon. For the evaluation of solid consistency, a soft Brazilian cookie $(2.2 \mathrm{~g})$ immersed in the solution of liquid barium was offered. The cookie was swallowed after chewing, with swallows analyzed in real time and frame by frame (60 frames per second). Patients were instructed not to use bronchodilators within a period of 24 hours before performing videofluoroscopy.

The following were timed features: 1$)$ onset of propulsive tongue tip movement at the maxillary incisors; 2) onset and end of the contact of the soft palate with the posterior pharyngeal wall; 3) passage of the bolus head through the fauces; 4) passage of the bolus tail through the fauces; 5) onset and end of hyoid movement; 6) onset and offset of upper esophageal sphincter (UES) opening; 7) onset and offset of laryngeal vestibular closure; 8) time that the larynx reached the maximal superior movement; and 9) time of the end of laryngeal maximal superior movement and onset of the descent movement of the larynx.

The duration of the following movements during swallowing were measured:

1. Oral transit: tongue tip at incisors to passage of the bolus tail through the fauces.

2. Maximal glossopalatal opening: time from the initial contact of the soft palate with the posterior pharyngeal wall to the end of the contact of the soft palate with the posterior pharyngeal wall.

3. Pharyngeal transit: bolus tail at fauces to offset of UES opening.

4. Pharyngeal clearance: bolus head at fauces to the offset of UES opening.
5. UES transit: time interval between the onset and offset of UES opening.

6. Maximal laryngeal elevation: interval from the moment the larynx reached its most superior position until it began its descent.

7. Duration of hyoid movement: time interval between onset and end of hyoid movement.

8. Laryngeal vestibular closure: interval between onset of complete laryngeal vestibule closure and onset of vestibule opening.

9. Oral-pharyngeal transit: interval between the tongue tip at incisors to the offset of UES opening.

To evaluate the possibility of penetration and aspiration, we used the previously described eight-point penetration aspiration scale. Penetration was defined as the passage of material into the larynx that does not pass below the vocal folds, and aspiration as the passage of material below the level of the vocal folds. ${ }^{14}$

\section{Statistical analysis}

Statistical analysis was performed by the Center for Quantitative Methods, Medical School of Ribeirão Preto, University of São Paulo (Center for Quantitative Methods [CEMEQ]). A linear model was used with mixed effects (random and fixed effects) in which the responses of the same subject were grouped and the assumption of independence between observations within the same group was not appropriate. ${ }^{15}$ Bolus volume and consistency (liquid $-5 \mathrm{~mL}$ and $10 \mathrm{~mL}$; paste $-5 \mathrm{~mL}$ and 10 $\mathrm{mL}$; and solid) were considered as fixed effects and subjects (patients and controls) were considered to be random effects. To use this model, it is necessary that their residues have normal distribution with zero mean and constant variance. To meet this assumption, changes were needed in the response variable. The model adjustment was done using PROC MIXED of SAS version $9 .{ }^{16}$ Correlation coefficient between pharyngeal transit duration and FVC, and between pharyngeal transit duration and $\mathrm{FEV}_{1}$, was calculated by Spearman's correlation coefficient. The differences were considered significant when $P<0.05$. The results are shown as mean and standard deviation.

\section{Results}

With liquid barium, the duration of pharyngeal transit $(5 \mathrm{~mL}$, mean [standard deviation]: controls - 0.23 [0.06] seconds; COPD $-0.29[0.05]$ seconds; $P=0.002$; Figure 1 ), laryngeal vestibular closure $(5 \mathrm{~mL}$, mean [standard deviation]: controls -0.37 [0.05] seconds; COPD - 0.56 [0.42] seconds; $P=0.011$ ), and hyoid movement $(5 \mathrm{~mL}$, mean [standard deviation]: controls - 0.48 [0.13] seconds; COPD - 0.63 [0.22] seconds; 


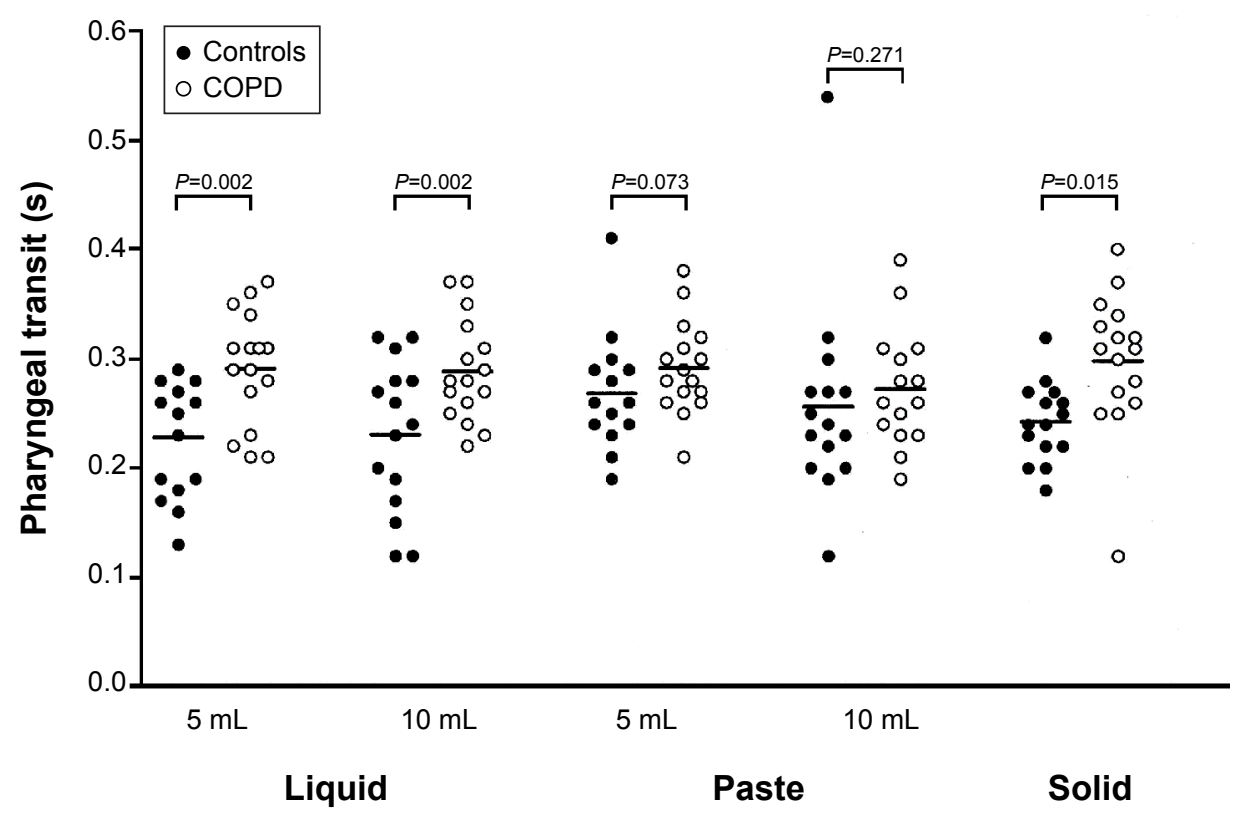

Figure I Pharyngeal transit duration in COPD patients and controls, in seconds, after swallows of liquid, paste, and solid boluses.

Note: The horizontal bar represents the mean.

Abbreviation: COPD, chronic obstructive pulmonary disease.

$P=0.001)$ were longer in patients with COPD than in controls, with the volumes of $5 \mathrm{~mL}$ and $10 \mathrm{~mL}$ (Table 2).

The duration of events was longer in COPD patients than controls with the $5 \mathrm{~mL}$ paste bolus in oral-pharyngeal transit duration (mean [standard deviation]: controls -0.61 [0.21] seconds; COPD -0.80 [0.36] seconds; $P=0.047$; Table 3), and with the solid bolus in oral-pharyngeal transit (mean [standard deviation]: controls - 0.53 [0.16] seconds; COPD - 0.69 [0.34] seconds; $P=0.022$ ) and pharyngeal transit (mean [standard deviation]: controls -0.24 [0.06] seconds; COPD - 0.30 [0.06]; $P=0.015$; Table 4).

The difference between the duration of maximal laryngeal elevation and the duration of pharyngeal transit was higher in control subjects than patients with COPD $(P<0.05$; Figure 2).

During the videofluoroscopy, there was no penetration or aspiration in either group for all volumes of liquid and paste bolus or for solid bolus, which corresponds to grade 1 in the penetration-aspiration scale.

There was no correlation between the results of FVC and $\mathrm{FEV}_{1}$ with the pharyngeal transit duration in COPD patients and controls $(P>0.05$; Table 5).

\section{Discussion}

Patients with COPD have an increased prevalence of oral-pharyngeal dysphagia as a consequence of impaired

Table 2 Duration of movements and transit, in seconds, in patients with COPD and controls after swallowing of $5 \mathrm{~mL}$ and $10 \mathrm{~mL}$ of liquid barium

\begin{tabular}{|c|c|c|c|c|c|c|}
\hline \multirow[t]{2}{*}{ Liquid } & \multicolumn{3}{|l|}{$5 \mathrm{~mL}$} & \multicolumn{3}{|l|}{$10 \mathrm{~mL}$} \\
\hline & Controls & COPD & P-value & Controls & COPD & P-value \\
\hline Oral transit & $0.36(0.15)$ & $0.32(0.13)$ & 0.332 & $0.36(0.16)$ & $0.32(0.15)$ & 0.347 \\
\hline Maximal glossopalatal opening & $0.19(0.09)$ & $0.22(0.15)$ & 0.672 & $0.25(0.2 I)$ & $0.26(0.17)$ & 0.252 \\
\hline Laryngeal vestibular closure & $0.37(0.05)$ & $0.56(0.42)$ & 0.011 & $0.36(0.07)$ & $0.42(0.15)$ & 0.038 \\
\hline Hyoid movement & $0.48(0.13)$ & $0.63(0.22)$ & 0.001 & $0.44(0.09)$ & $0.56(0.17)$ & 0.001 \\
\hline Laryngeal elevation & $0.29(0.12)$ & $0.33(0.09)$ & 0.053 & $0.29(0.09)$ & $0.32(0.09)$ & 0.274 \\
\hline Pharyngeal transit & $0.23(0.06)$ & $0.29(0.05)$ & 0.002 & $0.23(0.07)$ & $0.29(0.06)$ & 0.002 \\
\hline Pharyngeal clearance & $0.36(0.08)$ & $0.41(0.09)$ & 0.113 & $0.38(0.09)$ & $0.43(0.09)$ & 0.130 \\
\hline UES opening & $0.25(0.13)$ & $0.25(0.05)$ & 0.560 & $0.26(0.06)$ & $0.29(0.04)$ & 0.101 \\
\hline Oropharyngeal transit & $0.59(0.16)$ & $0.62(0.15)$ & 0.515 & $0.59(0.19)$ & $0.60(0.16)$ & 0.609 \\
\hline
\end{tabular}

Note: Data expressed as mean (standard deviation). Bolded data are statistically significant $(P<0.05)$.

Abbreviations: COPD, chronic obstructive pulmonary disease; UES, upper esophageal sphincter. 
Table 3 Duration of movements and transit, in seconds, in patients with COPD and controls after swallowing of $5 \mathrm{~mL}$ and $10 \mathrm{~mL}$ of paste barium

\begin{tabular}{|c|c|c|c|c|c|c|}
\hline \multirow[t]{2}{*}{ Paste } & \multicolumn{3}{|l|}{$5 \mathrm{~mL}$} & \multicolumn{3}{|l|}{$10 \mathrm{~mL}$} \\
\hline & Controls & COPD & $P$-value & Controls & COPD & $P$-value \\
\hline Oral transit & $0.38(0.24)$ & $0.50(0.34)$ & 0.216 & $0.39(0.25)$ & $0.36(0.24)$ & 0.301 \\
\hline Maximal glossopalatal opening & $0.35(0.29)$ & $0.31(0.23)$ & 0.553 & $0.27(0.14)$ & $0.38(0.27)$ & 0.140 \\
\hline Laryngeal vestibular closure & $0.36(0.06)$ & $0.37(0.76)$ & 0.766 & $0.34(0.06)$ & $0.37(0.08)$ & 0.151 \\
\hline Hyoid movement & $0.5 I(0.18)$ & $0.57(0.17)$ & 0.144 & $0.46(0.14)$ & $0.50(0.11)$ & 0.165 \\
\hline Laryngeal elevation & $0.29(0.07)$ & $0.29(0.06)$ & 0.897 & $0.29(0.10)$ & $0.29(0.09)$ & 0.836 \\
\hline Pharyngeal transit & $0.26(0.08)$ & $0.29(0.05)$ & 0.073 & $0.25(0.09)$ & $0.27(0.06)$ & 0.271 \\
\hline Pharyngeal clearance & $0.40(0.14)$ & $0.50(0.27)$ & 0.060 & $0.42(0.12)$ & $0.45(0.17)$ & 0.534 \\
\hline UES opening & $0.22(0.07)$ & $0.22(0.04)$ & 0.897 & $0.24(0.10)$ & $0.30(0.05)$ & 0.877 \\
\hline Oropharyngeal transit & $0.6 \mathrm{I}(0.2 \mathrm{I})$ & $0.80(0.36)$ & 0.047 & $0.61(0.19)$ & $0.63(0.24)$ & 0.805 \\
\hline
\end{tabular}

Note: Data expressed as mean (standard deviation). Bolded data are statistically significant $(P<0.05)$.

Abbreviations: COPD, chronic obstructive pulmonary disease; UES, upper esophageal sphincter.

respiration and swallowing coordination function. ${ }^{17}$ Reported characteristics of dysphagia in individuals with COPD include oral and pharyngeal stasis, ${ }^{5}$ delayed swallow reflex, ${ }^{5}$ reduced laryngeal elevation during swallowing, ${ }^{5}$ cricopharyngeal dysfunction, ${ }^{18}$ increased frequency of compensatory protective swallow maneuvers, ${ }^{5}$ laryngeal penetration,,${ }^{19}$ and aspiration. ${ }^{5}$

In this study, the duration of the laryngeal vestibule closure for the group of patients was higher than that found in the control group for the liquid consistency. Longer vocal fold closure may be a protective measure to avoid the risk of laryngotracheal aspiration. Protective measures were spontaneously used by individuals with COPD, as increased duration of air path closure decreases the risk of aspiration. ${ }^{5}$ Penetration/aspiration may depend on greater volume amounts of fluid being swallowed, ${ }^{19}$ amounts greater than those used during the videofluoroscopic examination in this study.

Studies have shown that the closure of the laryngeal vestibule during swallowing function occurs through sequential

Table 4 Duration of movements and transit, in seconds, in patients with COPD and controls after swallowing of solid bolus

\begin{tabular}{llll}
\hline Solid & Controls & COPD & $P$-value \\
\hline Oral transit & $0.29(0.13)$ & $0.39(0.32)$ & 0.268 \\
Maximal glossopalatal opening & $0.26(0.20)$ & $0.24(0.10)$ & 0.867 \\
Laryngeal vestibular closure & $0.36(0.06)$ & $0.35(0.07)$ & 0.674 \\
Hyoid movement & $0.56(0.20)$ & $0.53(0.10)$ & 0.706 \\
Laryngeal elevation & $0.30(0.09)$ & $0.29(0.06)$ & 0.915 \\
Pharyngeal transit & $0.24(0.06)$ & $0.30(0.06)$ & $\mathbf{0 . 0 1 5}$ \\
Pharyngeal clearance & $0.36(0.10)$ & $0.44(0.26)$ & 0.150 \\
UES opening & $0.20(0.04)$ & $0.21(0.05)$ & 0.378 \\
Oropharyngeal transit & $0.53(0.16)$ & $0.69(0.34)$ & $\mathbf{0 . 0 2 2}$ \\
\hline
\end{tabular}

Note: Data expressed as mean (standard deviation). The bolded data indicate the $P$-values were $<0.05$.

Abbreviations: COPD, chronic obstructive pulmonary disease; UES, upper esophageal sphincter. events encompassing the rise of the muscle complex and contraction of intrinsic laryngeal muscles. ${ }^{20,21}$ Therefore, these factors can be reasonably assumed to also be present in the COPD group studied; thus, the structures involved in airway protection may have adjusted and adapted in the sequence of events of swallowing to prevent the occurrence of aspiration.

Longer transit is in synchrony with the duration of the closure of the vocal folds and the duration of movement of the hyoid, showing both variables over an extended time. The adduction of the vocal folds begins at the first drive of the bolus toward the pharynx. ${ }^{21}$ Aspiration may occur during swallowing when the closing of the vocal folds does not occur at the exact time. ${ }^{22}$ The longer transit time through the pharynx increases the risk of aspiration. ${ }^{23}$ Swallowing apnea is maintained during the pharyngeal phase of swallowing and a longer duration of this phase needs a longer apnea for a safe passage of the bolus. ${ }^{24,25}$ However, the difference between laryngeal elevation duration and pharyngeal transit is lower in COPD patients than in controls, a situation which increases the risk of aspiration. Pharyngeal transit duration was not correlated with $\mathrm{FVC}$ and $\mathrm{FEV}_{1}$ values, suggesting that abnormal pulmonary function causes adaptations of pharyngeal transit not related with the intensity of the abnormality, at least in the stable phase of the disease.

The duration of pharyngeal transit observed in the COPD group may be related to insufficient glottal pressure, considering that these patients have reduced expiratory flow. ${ }^{26}$ Thus, afferent information stemming from the respiratory system modifies the response of efferent swallowing, so that this adjustment occurs due to the proximity of the central functions of swallowing and breathing. Adjustments to the length of the pharyngoesophageal transit may be related to the disease itself. ${ }^{24}$ The lower pressure gradient between the 


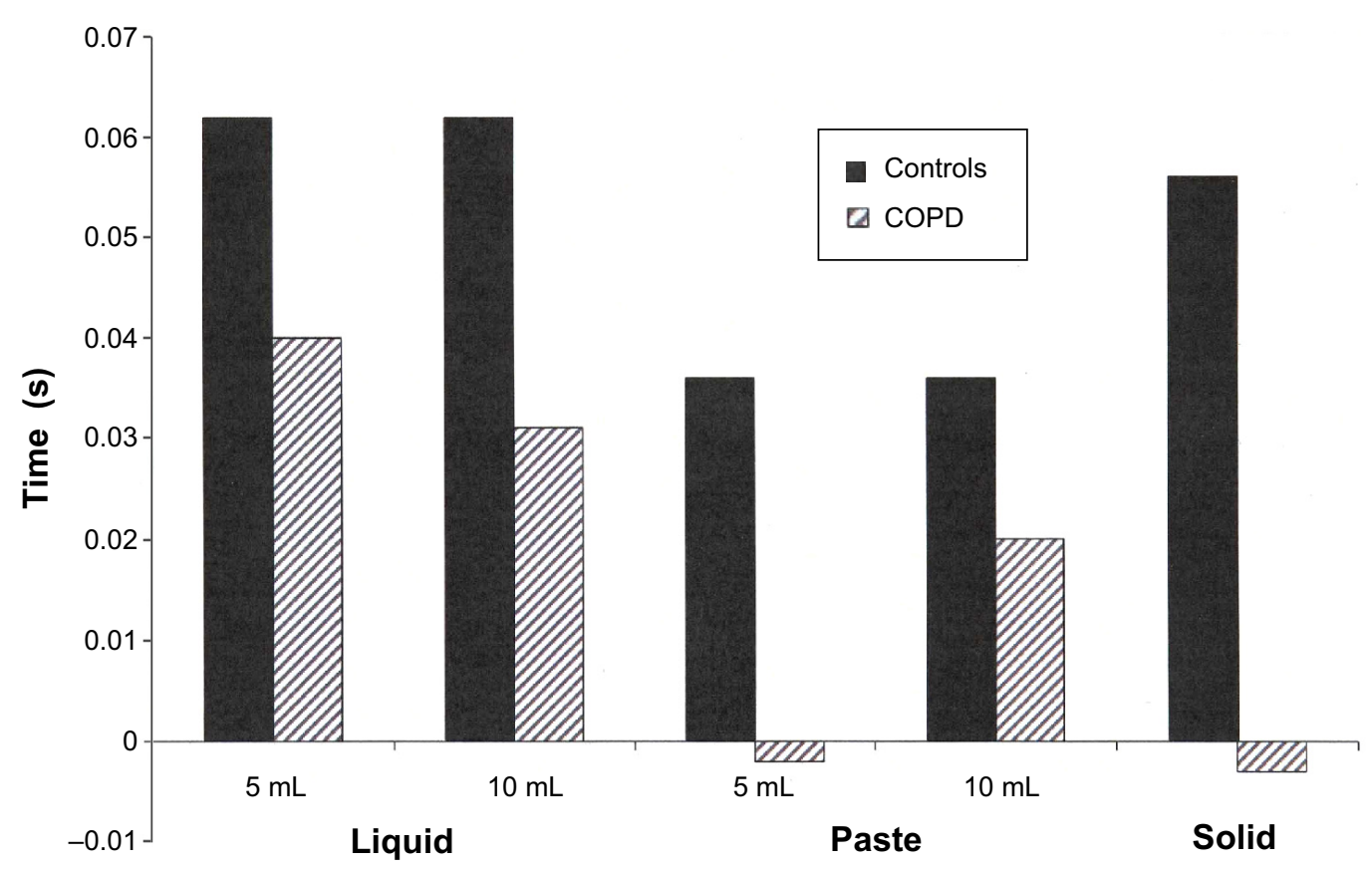

Figure 2 Difference between the duration of laryngeal elevation and the duration of pharyngeal transit, in seconds, in patients with COPD ( $\mathrm{n}=16)$ and controls ( $\mathrm{n}=15$ ). Notes: Results are the mean of individual differences. $P<0.05$ COPD versus controls.

Abbreviation: COPD, chronic obstructive pulmonary disease.

hypopharynx and esophagus, which occurs when swallowing is performed in the inspiratory phase, ${ }^{26}$ likely influences the duration but not the coordination of the pharyngeal phase of swallowing.

Aspiration occurred in $21 \%$ of COPD patients in the acute stages of the disease. ${ }^{2}$ The videofluoroscopy findings in our study showed no occurrence of aspiration, which could be explained in part due to the patients being studied during a stable phase of the disease. However, the simultaneous evaluation of respiration and swallowing was not performed, which could support this hypothesis. Due to changes in lung volume, patients with COPD may have increased risk of tracheal aspiration since the chance of aspiration in these individuals is higher during inspiration. ${ }^{5,27}$ The presence of inspiration, before swallowing apnea, generates more negative pressure in the trachea, which can increase this risk. ${ }^{26}$ It has been described that individuals with COPD are fatigued for a period of time after eating, with swallows becoming more frequent and increased breath recovery volume, leading to an increased risk of aspiration. ${ }^{9}$ Despite the respiratory changes in the patients, the nonoccurrence of aspiration may have been favored by the coordination of the sequential events of swallowing, which may represent adaptations or adjustments in the coordination of the swallowing function in order to support the respiratory changes in this disease, and to maintain as close as possible to the normal sequence of

Table 5 Correlation coefficient between the pharyngeal transit duration, FVC, and FEV, in patients with COPD and controls with swallows of liquid, paste, and solid boluses

\begin{tabular}{|c|c|c|c|c|c|c|c|c|}
\hline & \multicolumn{4}{|c|}{ Controls } & \multicolumn{4}{|c|}{ COPD } \\
\hline & \multicolumn{2}{|l|}{ FVC } & \multicolumn{2}{|l|}{ FEV $_{1}$} & \multicolumn{2}{|c|}{ FVC } & \multicolumn{2}{|l|}{ FEV } \\
\hline & rho & $P$-value & rho & $P$-value & rho & $P$-value & rho & $P$-value \\
\hline \multicolumn{9}{|l|}{ Liquid } \\
\hline $5 \mathrm{~mL}$ & -0.47 & 0.084 & -0.28 & 0.312 & 0.33 & 0.215 & -0.02 & 0.931 \\
\hline $10 \mathrm{~mL}$ & -0.29 & 0.291 & -0.19 & $0.50 \mathrm{I}$ & 0.23 & 0.382 & 0.23 & 0.396 \\
\hline \multicolumn{9}{|l|}{ Paste } \\
\hline $5 \mathrm{~mL}$ & -0.38 & 0.166 & -0.35 & 0.214 & 0.34 & 0.196 & 0.21 & 0.432 \\
\hline $10 \mathrm{~mL}$ & -0.42 & 0.128 & -0.30 & 0.286 & 0.50 & 0.051 & -0.01 & 0.976 \\
\hline Solid & $-0.4 \mathrm{I}$ & 0.134 & -0.34 & 0.225 & 0.15 & 0.578 & 0.06 & 0.812 \\
\hline
\end{tabular}

Abbreviations: COPD, chronic obstructive pulmonary disease; $\mathrm{FEV}_{\text {, }}$, forced expiratory volume in I second; FVC, forced vital capacity; rho, Spearman's correlation coefficient. 
events during the execution of the function in order to avoid respiratory complications. In patients with primary diagnosis of COPD and dysphagia, the risk of laryngeal penetration and aspiration was minimized by strategies during the swallowing function. ${ }^{2}$ Presence of protective measures may reduce the risk of aspiration. ${ }^{5}$

Integrity of swallowing exists when the subglottal pressure is positive ${ }^{10}$ therefore, we can assume that when this pressure is reduced, as in COPD, the risk of aspiration increases. As stated above, the adjustments in the central swallowing function, due to respiratory changes, ${ }^{28}$ likely made the transit slower. This mechanism must not be present in all patients, or it must be barely detectable, since it is known that the risk of aspiration is present in COPD., ${ }^{7,9}$

Another explanation for the absence of aspiration by the aggregation of the bolus would be an extension of oral-pharyngeal swallowing and apnea occurrence before aggregation of the bolus in the hypopharynx. ${ }^{25}$

Patients with advanced COPD often show decreased body weight associated with a decreased dietary intake, which may be caused by diminished physical activity, a depressive tendency, or dyspnea while eating. ${ }^{29}$ Weight loss is associated with increase in death rates. ${ }^{30}$ These patients ingest significantly less meal volume when compared with normal volunteers, with some grade of desaturation during the meal. ${ }^{31}$ Swallowing alterations may contribute to weight loss and should be the focus for treatment before they cause malnutrition. The increase in pharyngeal transit duration is small. It is possible that at this stage of the disease, in which there are compensations, this increase may not cause dysphagia or airway complications. This may be a problem when the compensations to sustain a safe and efficient swallow are not enough.

The results of this investigation are in concordance with a recent publication, which showed longer pharyngeal transit duration in patients with COPD. ${ }^{32}$

There are some limitations in this investigation. Although the sample size was small, it was enough to reach conclusions and to demonstrate the effect of the disease on swallowing. It was not possible to investigate respiratory function simultaneously with swallowing, which could add more information.

In conclusion, patients with COPD have a longer mean pharyngeal transit than normal subjects, but there is a significant overlap between individual results. The difference between the duration of maximal laryngeal elevation and pharyngeal transit is smaller in COPD patients than controls.

\section{Disclosure}

The authors report no conflicts of interest in this work.

\section{References}

1. GOLD - Global Initiative for Chronic Obstructive Lung Disease. Global strategy for the diagnosis, management, and prevention of chronic obstructive pulmonary disease. Bethesda: National Institutes of Health, 2003.

2. Good-Fratturelli MD, Curlee RF, Holle JL. Prevalence and nature of dysphagia in VA patients with COPD referred for videofluroscopic swallow examination. J Commun Disord. 2000;33(2):93-110.

3. Martin-Harris B, McFarland DH. Coordination of deglutition and respiration. In: Shaker R, Belafsky PC, Postma GN, Easterling C, editors. Principles of deglutition. New York: Springer; 2013:25-34.

4. Martin-Harris B. Clinical implications of respiratory-swallowing interations. Curr Opin Otolaryngol Head Neck Surg. 2008;16(3): 194-199.

5. Mokhlesi B, Logemann JA, Rademaker AW, Stangl CA, Corbridge TC. Oropharyngeal deglutition in stable COPD. Chest. 2002;121(2): 361-369.

6. Mokhlesi B, Morris AL, Huang CF, Curcio AJ, Barrett TA, Kamp DW. Increased prevalence of gastroesophageal reflux symptoms in patients with COPD. Chest. 2001;119(4):1043-1048.

7. Coelho CA. Preliminary findings on the nature of dysphagia in patients with chronic obstructive pulmonary disease. Dysphagia. 1987;2(1): $28-31$.

8. Terada K, Muro S, Ohara T, et al. Abnormal swallowing reflex and COPD exacerbations. Chest. 2010;137(2):326-332.

9. Shaker R, Li Q, Ren J, et al. Coordination of deglutition and phases of respiration: effect of aging, tachypnea, bolus volume, and chronic obstructive pulmonary disease. Am J Physiol. 1992;263(5 Pt 1):G750-G755.

10. Gross RD, Atwood CW Jr, Ross SB, Olszewski JW, Eichhorn KA. The coordination of breathing and swallowing in chronic obstructive pulmonary disease. Am J Respir Crit Care Med. 2009;179(7):559-565.

11. Smith J, Wolkove N, Colacone A, Kreisman H. Coordination of eating, drinking and breathing in adults. Chest. 1989;96(3):578-582.

12. Crapo RO, Morris AH, Gardner RM. Reference spirometric values using techniques and equipment that meet ATS recommendations. $\mathrm{Am}$ Rev Respir Dis. 1981;123(6):659-664.

13. Crapo RO, Morris AH, Clayton PD, Nixon CR. Lung volumes in healthy nonsmoking adults. Bull Eur Physiopathol Respir. 1982;18(3): 419-425.

14. Rosenbek JC, Robbins JA, Roecker EB, Coyle JL, Wood JL. A penetration-aspiration scale. Dysphagia. 1996;11(2):93-98.

15. Schall R. Estimation in generalized linear models with random effects. Biometrika. 1991;78(4):719-727.

16. Littel RC, Milliken GA, Stroup WW, Wolfinger RD, Scholenberg O SAS for mixed models. Second Edition, Cary, NC: SAS Institute Inc., 2006.

17. McKinstry A, Tranter M, Sweeney J. Outcomes of dysphagia intervention in a pulmonary rehabilitation program. Dysphagia. 2010;25(2): 104-111.

18. Stein M, Williams AJ, Grossman F, Weinberg AS, Zuckerbraun L. Cricopharyngeal dysfunction in chronic obstructive pulmonary disease. Chest. 1990;97(2):347-352.

19. Cvejic L, Harding R, Churchward T, et al. Laryngeal penetration and aspiration in individuals with stable COPD. Respirology. 2011;16(2): 269-275.

20. Kim Y, McCullough GH, Asp CW. Temporal measurements of pharyngeal swallowing in normal populations. Dysphagia. 2005; 20(4):290-296.

21. Shaker R, Dodds WJ, Dantas RO, Hogan WJ, Arndorfer RC. Coordination of deglutitive glottic closure with oropharyngeal swallowing Gastroenterology. 1990;98(6):1478-1484.

22. Kendall KA, Leonard RJ, McKenzie S. Airway protection: evaluation with videofluoroscopy. Dysphagia. 2004;19(2):65-70. 
23. Kendal KA, McKenzie S, Leonard RJ, Gonçalves MI, Walker A. Timing of events in normal swallowing: a videofluoroscopic study. Dysphagia. 2000;15(2):74-83.

24. Paydarfar D, Gilbert RJ, Popell CS, Nassab PF. Respiratory phase ressetting and airflow changes induced by swallowing in humans. J Physiol. 1995;483(Pt 1):273-288.

25. Palmer JB, Hiiemae KM. Eating and breathing: interactions between respiration and feeding on solid food. Dysphagia. 2003;18(3):169-178.

26. Kawasaki M, Ogura JH, Takenouchi S. Neurophysiologic observations of normal deglutition. I. Its relationship to the respiratory cycle. Laryngoscope. 1964;74:1747-1765.

27. Kijima M, Isono S, Nishino T. Modulation of swallowing reflex by lung volume changes. Am J Respir Crit Care Med. 2000;162(5):1855-1858.

28. Nishino T, Yonezawa T, Honda Y. Effects of swallowing on the pattern of continuous respiration in human adults. Am Rev Respir Dis. 1985; 132(6):1219-1222.
29. Itoh M, Tsuji T, Nemoto K, Nakamura H, Aoshiba K. Undernutrition in patients with COPD and its treatment. Nutrients. 2013;5(4): 1316-1335.

30. Wilson DO, Rogers RM, Wright EC, Anthonisen NR. Body weight in chronic obstructive pulmonary disease. The National Institutes of Health Intermittent Positive-Pressure Breathing Trial. Am Rev Respir Dis. 1989;139(6):1435-1438.

31. Cassiani RA, Santos CM, Baddini-Martinez J, Dantas RO. Arterial oxygen saturation and heart rate during a meal in chronic obstructive pulmonary disease. International Research Journal of Pharmacy and Pharmacology. 2011;1(6):119-125.

32. de Deus Chaves R, Chiarion Sassi F, Davison Mangilli L, et al. Swallowing transit times and valleculae residue in stable chronic obstructive pulmonary disease. BMC Pulm Med. 2014;14:62.

\section{Publish your work in this journal}

The International Journal of COPD is an international, peer-reviewed journal of therapeutics and pharmacology focusing on concise rapid reporting of clinical studies and reviews in COPD. Special focus is given to the pathophysiological processes underlying the disease, intervention programs, patient focused education, and self management protocols.

\section{Dovepress}

This journal is indexed on PubMed Central, MedLine and CAS. The manuscript management system is completely online and includes a very quick and fair peer-review system, which is all easy to use. Visit $\mathrm{http}: / / \mathrm{www}$.dovepress.com/testimonials.php to read real quotes from published authors. 